\title{
The Prevalence of Equine Leptospirosis in New York State
}

\author{
Rachel S. BARWICK ${ }^{1}$, Hussni O. MOHAMMED ${ }^{1 *}$, Edward R. ATWILL ${ }^{2}$, \\ Patrick L. McDONOUGH ${ }^{1}$ and Maurice E. WHITE ${ }^{1}$
}

${ }^{1}$ Department of Population Medicine \& Diagnostic Science, College of Veterinary Medicine, Cornell University, Ithaca, NY 14853 and ${ }^{2}$ Department of Population Health \& Reproduction and Veterinary Medicine Extension, Veterinary Medicine Teaching and Research Center, 18830 Road 112, Tulare, CA 93274

We carried out a cross-sectional study to determine the seroprevalence of seven different serovars of Leptospira interrogans in horses in New York State and examine the geographic distribution of the disease in the state. A random sample of 2,967 horses was selected from the equine population in New York State using the 1988 New York State Equine Census as a sampling frame. The samples were tested for the presence of antibodies against seven serovars: L. pomona, L. hardjo, L. icterohaemorrhagiae, L. grippotyphosa, L. canicola, L. autumnalis, and L. bratislava. The microscopic agglutination test was used to determine seropositivity at a range of dilutions from 1:100 to 1:12800. A titer of $\geq 100$ was considered positive. We also examined the association between seroconversion at higher $(\geq 1600)$ titers among those serovars. Cluster analysis was used to examine the distribution of the disease for special pattern or clustering. The following prevalences were determined: L. pomona (7.6\%), L. hardjo (1.0\%), L. icterohaemorrhagiae (11.3\%), L. grippotyphosa (6.5\%), L. canicola (16.2\%), L. autumnalis (35.1\%), and L. bratislava (40.7\%). The majority of the titers for all serovars were relatively low. Most of the samples tested positive for L. pomona had titers ranging from 100 to 400 . For all the other serovars, most samples tested positive had titers ranging from 100 to 200 . We found significant associations of seroconversion between all pairs of serovars except L. grippotyphosa and L. pomona, and L. grippotyphosa and L. autumnalis.

Key words: epidemiology, equine, leptospirosis, prevalence
J. Equine Sci.

Vol. 9, No. 4

pp. 119-124, 1998
Leptospirosis is a zoonotic disease affecting humans, domestic and wild animals $[13,15]$. It is prevalent worldwide and is caused by a bacterium species Leptospira interrogans, which is subdivided into pathogenic serovars. Serologic evidence of exposure to L. interrogans is common in horses, and horses may be a maintenance host for L. bratislava $[10,17]$. Leptospirosis can cause clinical disease in horses [12, 23]. Clinical signs may include fever, jaundice, anorexia, and lethargy [12, 23]. Leptospirosis is associated with equine uveitis $[14,19$, 23], renal dysfunction [4] and liver dysfunction [1, 14]. Other important consequences of Leptospira infection in horses are abortion and stillbirth $[2,6-8,10,16]$. It appears that the reported number of abortions and stillbirths due to L. interrogans is increasing [2, 3, 7]. The prevalence of leptospirosis in different countries and

This article was submitted March 11, 1999 and was accepted March $19,1999$.

*corresponding author. regions is reported to vary widely $[10,13,25,27,28]$. Little has been done to examine the disease in horses of New York State. The objectives of our study were to: 1) estimate the prevalence and distribution of seven serovars of L. interrogans in the horses of New York State; and 2) examine the association between those serovars.

\section{Methods and Materials}

\section{Study Population}

The study population was selected from the 39,000 equine operations in the 1988 New York State Equine Census [21]. In order to recruit at least $1 \%$ of the target population, a total of 3,000 equine operations were randomly selected and solicited by mail to participate in this study. Of these, 864 operations agreed to participate. Five hundred and seventy-two operations consisting of 2,967 horses were included in this study. The remaining 


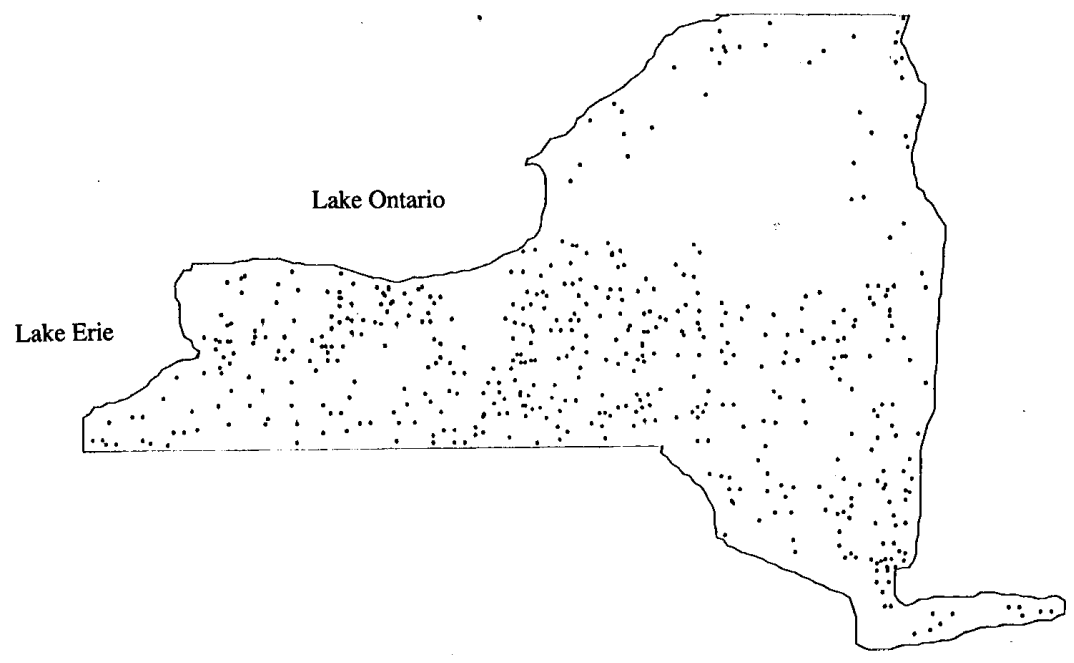

Fig. 1. The distribution of equine operations included in the prevalence study of L. interrogans serovars in New York State.

292 farms which we were unable to visit, in which 1,695 horses resided, were evenly distributed throughout the state. We had hoped to visit them in an attempt to have a larger representation of those counties with small equine populations but we were not able to visit the operations because the project was terminated in 8/93.

\section{Data collection}

Equine operations enrolled in the study were visited to collect blood samples and administer a questionnaire. The questionnaire was developed to collect geographic, demographic management, and health data on the study population. The questionnaire was administered by personal interview. The farms were visited from 5/91$8 / 93$, and an effort was made to visit different regions of the state from week to week to prevent seasonal and geographical biases. Blood samples were collected into sterile vacationers and stored in ice while transported to the New York State Diagnostic Laboratory, Cornell University. A total of 24 to 120 samples were collected and processed per week. Figure 1 shows the locations of the farms visited in New York State.

\section{Serology}

Sera were separated and stored at $-70^{\circ} \mathrm{C}$ until tested. Using the microscopic agglutination test (MAT) for seropositivity to the seven serovars of: $L$. pomona, $L$. hardjo, L. icterohaemorrhagiae, L. grippotyphosa, L. canicola, L. autumnalis, and L. bratislava [20]. All sera were initially screened at a dilution of 1:100. Those with a positive reaction were titrated in a serial two-fold dilution and the end-point titer was recorded. All sera reacting to a dilution of $\geq 1: 100$ were considered positive. The same observer determined all of the results of the MAT tests.

\section{Statistical analysis}

The prevalence of specific serovars of $L$. interrogans was computed as the proportion of samples that tested positive in the MAT for a specific serovar of all samples examined for that serovar. The county specific rate was computed as the proportion of seropositive samples among all samples from each county. These proportions were plotted, using a computerized graphics program [24].

The association between seroconversion in a horse at higher $(\geq 1600)$ titers among those serovars, as an indication of multiple exposure, was evaluated using the chi-square or fisher-exact tests (depending on the number of observations) in BMDP [5].

\section{Results}

Figure 2 shows the prevalence of the seven serovars of $L$. interrogans in the study population. The prevalence of these serovars varied from $1 \%$ for $L$. hardjo to $41 \%$ for L. bratislava. One thousand six hundred and fifty nine horses tested $(56 \%)$ were seropositive to at least one of the serovars.

The county specific prevalence for $L$. pomona is shown in Fig. 3. No samples were collected from Hamilton, Nassau, or Rockland counties. All other counties had at 


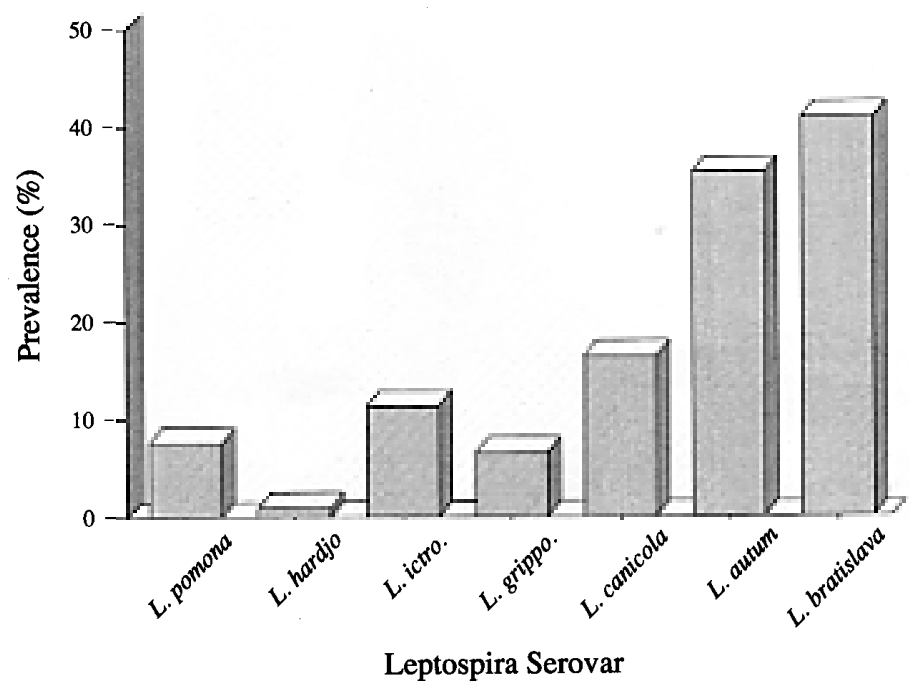

Fig. 2. The prevalence of L. interrogans serovars in the equine population of New York State.

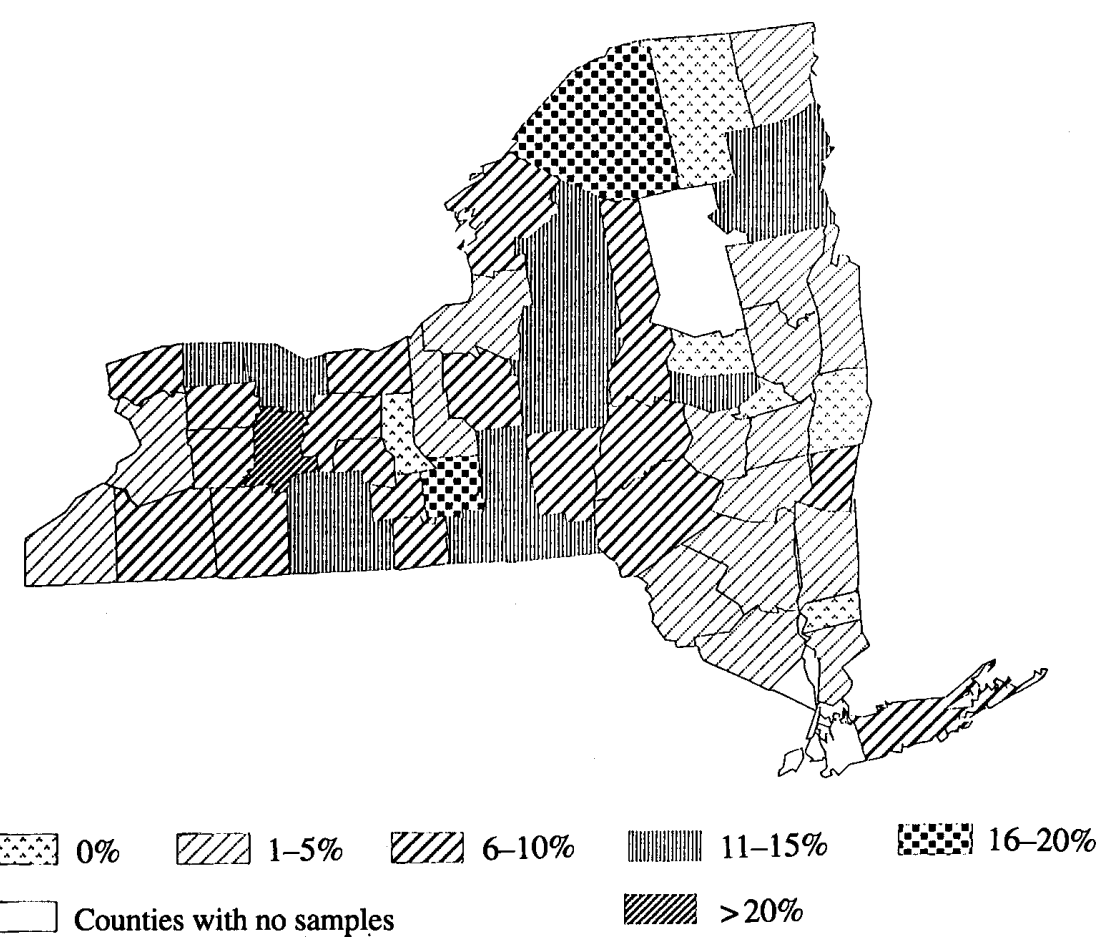

Fig. 3. The county-specific prevalence of L. pomona in the equine population in New York State.

least seven samples. Only one county had a prevalence above 20\% (Livingston; prevalence $=21.3 \%$ ). The majority of the counties had a prevalence above $6 \%$; these counties are located primarily in central and western New York State. On the other hand, the distribution of $L$. bratislava appeared to have no distinct pattern throughout the state (Fig. 4). Montgomery and Lewis counties had the highest prevalence for this serovar (67 and 63\%, respectively).

Table 1 shows the distribution of the titers among the 


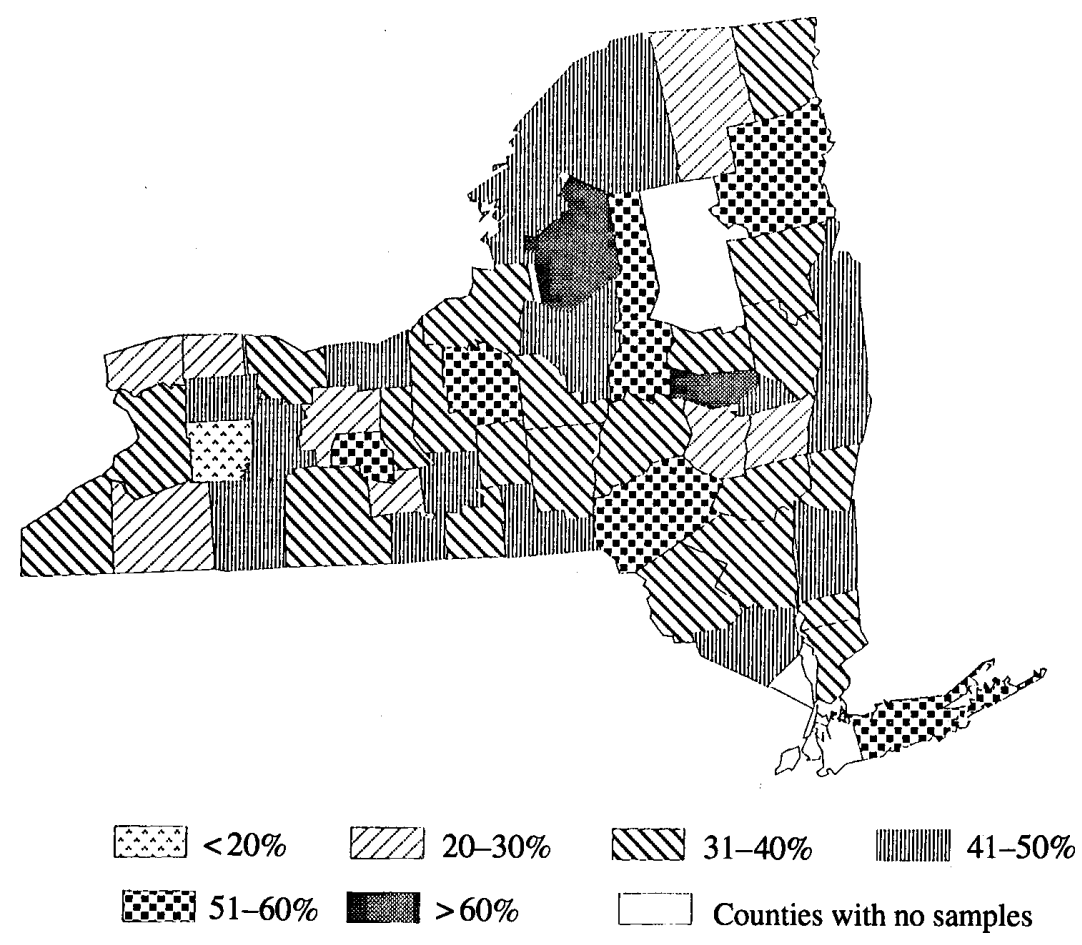

Fig. 4. The county-specific prevalence of L. bratislava in the equine population in New York State.

samples that tested positive. The majority of the titers for all serovars were relatively low. Most of the samples tested positive for L. pomona had titers ranging from 100 to 400 . For all the other serovars, most samples testing positive had titers ranging from 100 to 200 . L. pomona and L. autumnalis were the only serovars which had samples whose end-point titers were at a dilution of $1: 12,800$.

Table 2 shows the $\mathrm{p}$-values for the association between two serovars at higher $(\geq 1600)$ titers, as an indication of multiple exposure. There were significant associations between all pairs of serovars except $L$. grippotyphosa and L. pomona, and L. grippotyphosa and L. autumnalis.

\section{Discussion}

The objectives of the study were to determine the prevalence of seven $L$. interrogans and determine their distribution throughout New York State. A dilution of $\geq 1: 100$ was used as a cut-off point for seropositivity. Most laboratories using the MAT test as a diagnostic tool for serology in equine leptospirosis consider a dilution of 1:100 as positive [26]. There is a general belief that infections can be identified and non-specific reactions are less likely to occur at this dilution [26].

Figure 1 shows the wide range of prevalence of seven serovars of L. interrogans in New York State. L. hardjo has the lowest prevalence of $1 \%$. Of all horses tested, $40.7 \%$ tested positive to the serovar L. bratislava. This high prevalence suggests that horses might be a reservoir host for this serovar. However, there have been studies that have indicated an association between disease and infection of L. bratislava, but it is unclear what the significance is of this association [10]. Figure 2 shows that $L$. bratislava is widely distributed throughout New York State, with prevalences in Lewis and Montgomery counties greater than $60 \%$. There is no distinct pattern to the distribution of this serovar throughout the state. A high number of horses also reacted to L. autumnalis $(35.1 \%)$, but it is not clear what role this serovar plays in the disease, or if horses may serve as a maintenance host for this serovar.

L. pomona is the serovar often associated with clinical and pathological disease in the horse [2, 3, 10, 16, 23], and it is also widely distributed throughout the state (Fig. 3 ), although the overall prevalence $(7.6 \%)$ was lower than that of L. bratislava. Most counties had a prevalence of L. pomona greater than $6 \%$; these are located primarily in Central and Western New York. We do not believe 
Table 1. The distribution of the positive titers of the seven serovars of L. interrogans in the horses in New York State

\begin{tabular}{lrrrrrrrrr}
\hline & \multicolumn{8}{c}{ Titer } & Total \\
\cline { 2 - 8 } Serovar & 100 & 200 & 400 & 800 & 1600 & 3200 & 6400 & 12800 & $\begin{array}{c}\text { Tomber } \\
\text { number }\end{array}$ \\
\cline { 2 - 9 } L. pomona & 23.5 & 20.8 & 19.5 & 16.8 & 12.8 & 3.5 & 1.3 & 1.8 & 226 \\
L. hardjo & 83.9 & 9.7 & 3.2 & 3.2 & 0 & 0 & 0 & 0 & 31 \\
L. ictero. & 67.5 & 25.4 & 8.4 & 3.0 & 0.9 & 0.9 & 0 & 0 & 335 \\
L. grippo. & 53.1 & 28.4 & 8.8 & 7.2 & 2.1 & 0.52 & 0 & 0 & 194 \\
L. canicola & 51.3 & 31.9 & 12.5 & 2.5 & 1.0 & 0.42 & 0.42 & 0 & 480 \\
L. autumnalis & 53.3 & 27.1 & 10.0 & 5.6 & 2.0 & 0.38 & 0.38 & 0.19 & 1041 \\
L. bratislava & 50.0 & 30.5 & 12.2 & 4.4 & 2.0 & 0.5 & 0.5 & 0 & 1208 \\
\hline
\end{tabular}

Table 2. The significance of association between two serovars of $L$. interrogans from samples with positive titers $\geq 1600$

\begin{tabular}{llcccccc}
\hline Titer & & L. pomona & L. ictero. & L. grippo. & L. canicola & L. autum. & L. bratis. \\
\hline & L. ictero. & 0.0862 & - & 0.0117 & 0.0000 & 0.0031 & 0.0000 \\
& L. grippo. & 0.9277 & 0.0117 & - & 0.0175 & 0.9277 & 0.0649 \\
& L. canicola & 0.0073 & 0.0000 & 0.0175 & - & 0.0002 & 0.0000 \\
& L. autum. & $0.0000^{* *}$ & 0.0031 & 0.9277 & 0.0002 & - & $0.0000^{*}$ \\
$\geq 1600$ & L. bratis. & $0.0000^{* *}$ & 0.0000 & 0.0649 & 0.0000 & $0.0000^{*}$ & - \\
\hline
\end{tabular}

** $\mathrm{p}$-value calculated using chi-square test.

that this pattern is due to direct transmission among horses; however, if we were to speculate, the pattern may be due to geographical variability in soil type, climate, or wildlife distribution [2, 3]. Livingston, Tompkins, and St. Lawrence counties are those counties with the highest prevalences of L. pomona, with Livingston county having over $20 \%$ of the horses testing positive.

Our prevalence findings agree with previous studies conducted [10, 18, 28]. However, it is important to keep in mind that the prevalence of serovars can vary among regions (due to climate and geographical variations). Also, sampling biases may occur. This study was conducted with a true random sample of horses from New York State to minimize sampling bias.

In this study we found that $56 \%$ of the horses tested positive to at least one of the seven serovars. Many horses tested positive to multiple serovars. It is possible that there was multiple exposure to more than one serovar, but it also possible that some cross-reactivity occurred between the serovars. This could also help explain the abundance of low titers, as shown in Table 1. Because L. hardjo has a low prevalence of $1 \%$, and the majority of positive samples had a titer of 100 , this could indicate cross-reactivity, and not true infection. Since it is believed that cross-reactivity occurs predominately in lower titers we based our evaluation of the associations between serovars on samples which reacted at a dilution of $\geq 1: 1600$. We expect that any significant associations are based on multiple exposure to serovars and not crossreactivity. We found that multiple exposure is both common and probable. Previous studies have also found multiple infection to be common [14, 28]. All pairs of serovars were found to be significantly associated with one another except for the pairs of L. grippotyphosa and L. pomona (p-value $=0.9277)$, and L. grippotyphosa and $L$. autumnalis $(\mathrm{p}$-value $=0.9277)$.

The MAT test is a subjective test. To carry out this diagnostic procedure, the observer must determine if at least $50 \%$ of the antigen has agglutinated with the antibodies in the serum. In order to reduce observer variability in our study, only one observer (the senior author), was used to determine the results of all of the tests.

Studies should be continued to further understand the epidemiology of this disease. A better understanding will lead to the development of recommendations for horse owners on how to avoid equine Leptospira infection and improve preventive measures. This may not only help prevent equine infection, but infection of other mammals as well, including humans. 


\section{Acknowledgment}

This research was supported by funds from the Unrestricted Alumni Funds, College of Veterinary Medicine, Cornell University.

\section{References}

1. Barsoum, I.S., Botros, B.A.B., and Morcos, M.B. 1978. Equine leptospirosis with some clinical observations. Ann. Rech. Vet. 9: 115.

2. Bernard, W.V. 1993. Leptospirosis. Vet. Clin. of North Am: Equine Prac 9: 435-444.

3. Bernard, W.V. 1993. Leptospiral abortion and leptospiruria in horses from the same farm. J. Am. Vet. Med. Assoc. 202: 1285-1286.

4. Divers, T.J., Byars, T.D., and Shin, S.J. 1992. Renal dysfunction associated with infection of Leptospira interrogans in a horse. J. Am. Vet. Med. Assoc. 201: 1391-1392.

5. Dixon, W.J. 1992. BMDP Statistical Software Manual. University of California Press, Berkley, CA, 245328.

6. Donahue, J.M., Smith, B.J., Donahoe, J.K., Rigsby, C.L., Tramontin, R.R., Poonacha, K.B., and Wilson, M.A. 1992. Prevalence and serovars of leptospira involved in equine abortions in central Kentucky during the 1990 foaling season. J. Vet. Diagn. Invest. 4: 279-284.

7. Donahue, J.M., Smith, B.J., Poonacha, K.B., Donahoe, J.K., and Rigsby, C.L. 1995. Prevalence and serovars of leptospira involved in equine abortions in central Kentucky during the 19911993 foaling seasons. J. Vet. Diagn. Invest. 7: 87-91.

8. Donahue, J.M., Smith, B.J., Redmon, K.J., and Donahoe, J.K. 1991. Diagnosis \& prevalence of leptospira infection in aborted and stillborn horses. J. Vet. Diagn. Invest. 8: 148-151.

9. Ellis, W.A., Bryson, D.G., O'Brien, J.J., and Neill, S.D. 1983. Leptopiral infection in horses in aborted equine foetuses. Equine Vet.J. 15: 321-324.

10. Ellis, W.A., O'Brien, J.J., Cassells J.A., and Montgomery, J. 1983. Leptopiral infection in horses in Northern Ireland: Serological and microbiological findings. Equine Vet.J. 15: 317-320.

11. Ellis, W.A., Bryson, D.G., and McFerran, J.B. 1976. Abortion associated with mixed leptospira/equid herpesvirus 1 infection. Vet. Rec. 98: 218-219.

12. Hall, C.E. and Bryans, J.T. 1952. A case of leptospirosis in a horse. Cornell Vet. 44: 345-348.

13. Hanson, L.E. 1982. Leptospirosis in domestic animals: The public health perspective. J. Am. Vet. Med. Assoc. 12: 1505-1509.

14. Hathaway, S.C., Little, T.W.A., Finch, S.M., and Stevens, A.E. 1981. Leptospiral infection in horses in England: A serological study. Vet. Rec. 108: 396398.

15. Heath, S.E. and Johnson, R. 1994. Clinical Update: Leptospirosis. J. Am. Vet. Med. Assoc. 11: 1518-1523.

16. Hodgin, E.C., Miller D.A., and Lozano, F. 1989. Leptospira abortion in horses. J. Vet. Diagn. Invest. 1: 283-287.

17. Kitson-Piggot, A.W. and Prescott, J.F. 1987. Leptospirosis in horses in Ontario. Can.J. Vet. Res. 51: 448-451.

18. Lees, V.W. and Gale, S.P. 1994. Titers to Leptospira species in horses in Alberta. Can. Vet.J. 35: 636-640.

19. Matthews, A.G. Waitkins, S.A. and Palmer, M.F. 1987. Serological study of leptospiral infections and endogenous uveitis among horses and ponies in the United Kingdom. Equine Vet.J. 19: 125-128.

20. National Veterinary Services Laboratories. 1987. Microtiter technique for detection of leptospira antibodies. Proc. US Anim. Health. Assoc. 91: 65-73.

21. New York Agricultural Statistics Service 1989. New York Equine Survey 1988.

22. Poonacha, K.B., Donahue, R.C., Giles, R.C., Hong, C.B., Petrites-Murphy, M.B., Smith, B.J., Swerczek, T.W., Tramontin, R.R., and Tuttle, P.A. 1993. Leptospirosis in Equine Fetuses, Stillborn Foals, and Placentas. Vet. Pathol. 30: 362-369.

23. Roberts, S.J., York, C.J., and Robinson, J.W. 1952. An outbreak of leptospirosis in horses on a small farm. J. Am. Vet. Med. Assoc. 121: 237-242.

24. SAS Institute Inc. 1985. SAS/STAT Guide for personal computers. Version 6.03 edition, SAS Institute Inc., Cary, NC. p 378.

25. Slatter, D.H. and Hawkins, C.D. 1982. Prevalence of leptospiral titres in normal horses. Aust. Vet.J. 59: 84-86.

26. Stoenner, H.G. 1974. Summary report on the 1975 survey for leptospirosis in the United States. Proc. 79th Ann. Mtg. U.S. Anim. Health Assn., 145-147.

27. Swart, K.S., Calvert, K., and Meney, C. 1982. The prevalence of antibodies to serovars of Leptospira interrogans in horses. Aust. Vet. J. 59: 25-27.

28. Williams, D.M., Smith, B.J., Donahue, J.M., and Poonacha, K.B. 1994. Serological and microbiological findings on 3 farms with equine leptospiral abortions. Equine Vet.J. 26: 105-108. 